\title{
IPSS-R Risk Category High
}

National Cancer Institute

\section{Source}

National Cancer Institute. IPSS-R Risk Category High. NCI Thesaurus. Code C162683.

A total IPSS-R score of 5 to 6 , indicating high risk. 